\title{
Allele-specific gene expression in mammals: The curious case of the imprinted RNAs
}

\author{
Karl Pfeifer and Shirley M. Tilghman \\ Howard Hughes Medical Institute and Department of Molecular Biology, Princeton University, Princeton, New Jersey \\ 08544 USA
}

Mammals exhibit two epigenetic phenomena whose consequence is the silencing of one of two wild-type copies of a gene - X chromosome inactivation in females and parental imprinting of selected autosomal genes. As the mechanisms underlying these forms of gene dosage control are being elucidated, some striking similarities between them are being revealed. Of these similarities, none is more curious than the involvement of two noncoding RNAs in these processes, Xist, in the case of $\mathrm{X}$ chromosome inactivation, and $H 19$, an imprinted RNA on chromosome 7 . This article will explore the potential evolutionary relationship between $\mathrm{X}$ chromosome inactivation and imprinting by focusing on these unusual RNAs.

\section{The association between imprinting and H19 RNA}

The first imprinted gene identified in mammals was found, by chance, in the course of studies intended to elucidate the function of the fetal-specific growth factor, insulin-like growth factor II. DeChiara et al. (1990) had generated a mutation in the gene using homologous recombination in embryonic stem cells. When that mutation was inherited from fathers, the heterozygous offspring were $60 \%$ of normal size, but when the gene was maternally inherited, the offspring were normal-sized. The authors explained this genetic mystery by showing that only the paternal copy of the Igf2 gene is active in most tissues of the fetus (DeChiara et al. 1991).

Igf2 had been mapped to the distal third of mouse chromosome 7 in a region that had been implicated in imprinting by genetic analysis (Searle and Beechey 1990). Embryos that inherit the chromosomal region containing Igf2 exclusively from mothers die late in gestation. If the lack of Igf2 was the only defect in these embryos, they should have survived, suggesting that the distal end of chromosome 7 contained at least one other imprinted gene. $H 19$ was identified shortly thereafter as the second imprinted gene in the region (Bartolomei et al. 1991). Unexpectedly, its expression was the opposite to that of Igf2, that is, it was maternally expressed.

The discovery of H19's allele-specific expression only served to fuel the mystery surrounding this gene. It was originally identified in a differential screen for genes that were coregulated with an endoderm- and fetal-specific gene, $\alpha$-fetoprotein (AFP) (Pachnis et al. 1984, 1988). Since then, it has been identified in a variety of such screens, including ones to identify genes induced by differentiation of fibroblasts into muscle (Davis et al. 1987) and embryonic stem cells into primitive endoderm (Poirier et al. 1991). What made it unusual was the absence of a conserved open reading frame in the "mRNA," despite the fact that its gene structure and biosynthesis pointed to its being a conventional mRNA (Brannan et al. 1990). The patterns of sequence conservation among mammalian versions of the RNA suggested that aspects of both primary and secondary structure, not protein coding capacity, were being conserved (Tilghman et al. 1992). Although Leibovitch et al. (1991) used an antibody to detect a $29-\mathrm{kD}$ protein purported to be encoded by the human $\mathrm{H} 19$ gene, the specificity of the antibody has never been demonstrated, and the putative protein product is not conserved in any other mammalian species.

\section{The association between $X$ chromosome inactivation} and XIST RNA

Several years ago a second noncoding RNA that was expressed in an allele-specific manner was discovered in mammals. XIST RNA was first identified in humans as a transcript that mapped to the $\mathrm{X}$ chromosome inactivation center (XIC), a site required in cis for inactivation of the X chromosome (Brown et al. 1991). Surprisingly, its expression was derived exclusively from the inactive $\mathrm{X}$ chromosome, a property that is unique to XIST. Like $H 19$, it encodes no open reading frame conserved in the two mammalian homologs-human and mouse-identified to date (Brockdorff et al. 1991, 1992; Pizzuti et al. 1991; Brown et al. 1992). In fact, Hendrich et al. (1993) have recently shown that the degree of sequence conservation among $H 19$ and XIST homologs is very similar (see Fig. 3, below).

The XIST RNA in humans and its counterpart, Xist RNA in mice, were localized to the nucleus, and possibly 
even to the inactive $\mathrm{X}$ chromosome, although at the moment the in situ hybridization studies on which this conclusion is based cannot distinguish between the inactive $\mathrm{X}$ as the site of XIST transcription versus its localization (Brockdorff et al. 1992; Brown et al. 1992). Biochemical fractionation studies, on the other hand, place the majority of the human and mouse H19 RNAs in 28S-30S cytoplasmic particles, although they also indicate that a portion of the RNA may be nuclear (Brannan et al. 1990). This difference in localization represents a potentially significant difference in the properties of the two RNAs. However, in light of the fact that the two experiments were performed using very different methods, this difference could be more apparent than real. Until it is established in what cellular compartment each RNA functions, the significance of these studies remains uncertain.

\section{The role of DNA methylation in the allele-specific expression of Xist and $\mathrm{H19}$}

The parallels between $H 19$ and XIST extend to their mode of expression in mammals, in the sense that each is expressed within a chromosomal context in which one or more neighboring gene(s) is maintained in a silent configuration. In the case of $H 19$, it is the $5^{\prime}$ Igf2 gene that is silent on the maternal chromosome. For XIST, the silent neighbors encompass most of the inactive $\mathrm{X}$ chromosome. Recent work suggests that DNA methylation may underlie at least some part of the mechanisms controlling this allele-specific transcription.

The problem that allele specificity poses is very similar for imprinting and $\mathrm{X}$ chromosome inactivation: The transcriptional machinery must distinguish between the expressed and silent copies, and that distinction must be stable and heritable through many cell divisions. In the case of imprinting, this distinction is based solely on chromosomal origin-maternal versus paternal-and not on any instrinsic information in the DNA sequences of the alleles. One could envisage at least two ways in which DNA methylation could participate in allele-specific expression of genes. First, it could act as the primary mark that is established during gametogenesis to distinguish the alleles. Alternatively, DNA methylation could be a response to a primary mark, functioning to maintain differential gene expression. Distinguishing between these possibilities is crucial for understanding the mechanism of imprinting.

The argument in favor of a central role for DNA methylation in at least the early stages of Xist expression has recently come from work from Rastan's laboratory (Norris et al. 1994). The choice of which X chromosome to inactivate in eutherian mammals is a random one in all somatic cells. The only exceptions are the trophectoderm and endodermal cells in the extra-embryonic membranes, among the first cells to differentiate in early embryos. There the choice is paternal inactivation, and, in that sense, $\mathrm{X}$ chromosome inactivation can be considered to be imprinted (Takagi and Sasaki 1975; West et al. 1977). Norris et al. (1994) have recently shown that the paternal Xist allele becomes demethylated during meiosis and remains so until fertilization. They argue that the hypomethylation permits paternal-specific Xist expression by the four-cell stage, and thereby directs paternalspecific $\mathrm{X}$ chromosome inactivation in the earliest tissues to differentiate. Between the morula and blastocyst stages, a genome-wide demethylation (Monk et al. 1987; Kafri et al. 1992) presumably erases the paternal methylation in all other uncommitted embryonic cells, and the counting mechanism that inactivates all but one $\mathrm{X}$ chromosome with random choice is initiated. Even in these cells, the pattern of DNA methylation around the $X i s t$ gene is again consistent with a negative role for methylation, as demonstrated by methylation over the silent allele on the active X chromosome (Norris et al. 1994).

DNA methylation was first implicated in autosomal parental imprinting when it was noticed that some transgenes were methylated in a parental-specific manner, usually when inherited from mothers, and the methylation served to silence expression from the transgene in at least one instance (Hadchouel et al. 1987; Reik et al. 1987; Sapienza et al. 1987; Swain et al. 1987; Chaillet et al. 1991). After the first endogenous imprinted genes were identified, parental-specific methylation patterns were found in their environs, but the patterns were not always what was expected. For example, the insulin-like growth factor II receptor (Igf2r) gene, which is maternally expressed in mice (Barlow et al. 1991), is selectively methylated on the expressed maternal allele within an intron and on the silent paternal allele on the promoter (Stoger et al. 1993). However, only the maternal methylation is set during gametogenesis and maintained throughout development, a requirement for the mark. Likewise, a region upstream of the active paternal allele of Igf2 is differentially methylated (Sasaki et al. 1991). The differential methylation of the active alleles of these two imprinted genes ran counter to the expectation that methylation would perform a negative regulatory function. $H 19$, on the other hand, seemed to fulfill this expectation beautifully in that an 8- to $10-\mathrm{kb}$ domain that included $\sim 5 \mathrm{~kb}$ of its promoter and the gene itself were heavily methylated only on the silent paternal copy (Bartolomei et al. 1993; Brandeis et al. 1993; Ferguson-Smith et al. 1993).

The importance of DNA methylation in maintaining the imprint on these genes has been demonstrated recently by Li et al. $(1992,1993)$, who analyzed the impact of genome-wide demethylation in embryos lacking the maintenance methylase, DNA methyltransferase. They showed that in homozygous mutant embryos, the loss of DNA methylation results in the activation of the silent paternal $H 19$ gene, but the silencing of both Igf2 and Igf2r. Thus, for H19, DNA methylation acts negatively, whereas it must be a positive regulator for the other two genes.

\section{Are XIST and H19 involved in Allele-specific expression?}

The presence of genes for noncoding RNAs within at 
least two imprinted domains raises the possibility that they have some functional role to play, either in their own imprinting, or the imprinting of neighboring genes. The attractiveness of considering RNA as a regulatory molecule for imprinting is its ability to act in cis, unlike proteins, which must be translated in the cytoplasm. On the basis of its map position and its exclusive transcription from the inactive $\mathrm{X}$ chromosome, XIST could be the long sought after $\mathrm{X}$ chromosome inactivation center as has been suggested by several investigators. A word of caution is needed, however, because the defined genetic boundaries of $\mathrm{Xce}$ extend well beyond the borders of the XIST gene (P. Cooper et al. 1993; Heard et al. 1993; Lafreniere et al. 1993; Leppig et al. 1993). Notwithstanding this proviso, circumstantial evidence in favor of a role for $X I S T$ in X chromosome inactivation has been steadily mounting. XIST is not transcribed in XY males, which do not undergo $X$ chromosome inactivation (Brockdorff et al. 1991; Brown et al. 1991). Allelic differences at the $\mathrm{X}$ chromosome inactivation center in mice can affect the likelihood that an X chromosome will be chosen for inactivation in XX females cells (Cattanach et al. 1969; Cattanach and Papworth 1981; Johnson and Cattanach 1981). X chromosomes with "strong" Xce alleles are more likely to remain active than those with "weak" alleles. Those alleleic differences inversely correlate with levels of Xist RNA expression, in that the X chromosomes with strong $X c e$ alleles express less Xist than those with weak alleles (Brockdorff et al. 1991). Finally, the activation of Xist precedes $\mathrm{X}$ chromosome inactivation in mouse embryos, and therefore its expression is not a consequence of the process (Kay et al. 1993). Definitive evidence, however, awaits the analysis of mutations of the gene in mice. However, for the purposes of this article, we will accept the hypothesis that the decision to transcribe the Xist gene is mechanistically crucial to the silencing of the other genes on that $\mathrm{X}$ chromosome. Whether it is the act of Xist transcription per se, or the RNA product, acting in cis to maintain its own transcription or silence that of the neighboring genes remains a central issue for exploration.

For $H 19$, there are no data that argue that its RNA product is involved in either its own imprinting or the imprinting of Igf2. However, several observations suggest the possibility that the transcriptional imprinting of the $H 19$ and Igf2 genes are mechanistically linked, suggesting at least an indirect role for H19 in Igf2 imprinting. First, the two genes are very tightly linked and lie within $75 \mathrm{~kb}$ of one another on the distal end of chromosome 7 (Zemel et al. 1992). Second, they are expressed in an identical pattern during embryogenesis in cells of endoderm and mesoderm origin, and then repressed in most tissues after birth (Lee et al. 1990; Poirier et al. 1991). Several years ago, we proposed that the reciprocal imprinting of these two genes is mediated by a competition between them for a common set of regulatory elements (Fig. 1; Bartolomei and Tilghman 1992; Bartolomei et al. 1993). The competititon is driven by paternal-specific methylation of the $H 19$ gene, which silences that allele, thereby permitting Igf2 transcription. On the

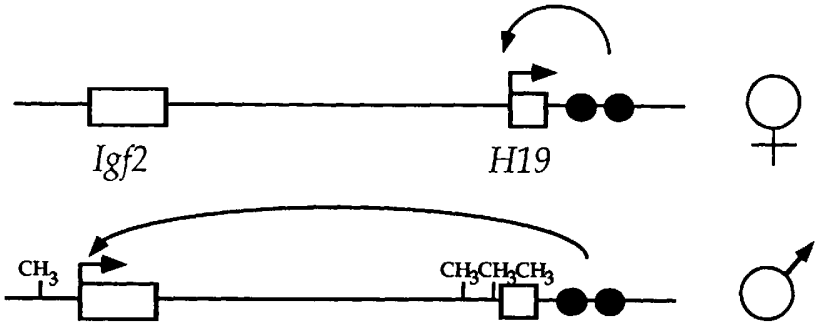

Figure 1. The enhancer competition model to explain the opposite imprinting of $H 19$ and Igf2. (D) The H19 and Igf2 genes, with the horizontal arrows indicating the transcribed alleles. (O) The two $H 19$ enhancers. The positions of allele-specific methylation of the paternal chromosome are indicated by the $\mathrm{CH}_{3}$ symbols. The single-lined arrows leading from the enhancers indicate the engagement of the enhancers with the $H 19$ gene on the maternal allele and the Igf2 gene on the paternal allele. The data for the methylation at Igf2 are taken from FergusonSmith et al. (1993), and the data for H19 from Bartolomei et al. (1993).

maternal chromosome, the $\mathrm{H} 19$ gene is fully active due to the absence of DNA methylation, and so by default, the maternal Igf2 gene is not transcribed.

Three observations are consistent with the model: The paternal methylation of $H 19$ acts as a negative signal, as judged by the reactivation of the paternally inherited gene in embryos lacking DNA methyltransferase $/ \mathrm{Li}$ et al. 1993); one of the strong enhancers downstream of the H19 gene is hypersensitive on both alleles, indicating that it is actively engaged in transcription on both parental chromosomes (Sasaki et al. 1992; Bartolomei et al. 1993); and the H19 gene, transposed to other chromosomal locations as a transgene, is still imprinted, unlike the majority of Igf2 transgenes (Bartolomei et al. 1993; Lee et al. 1993). The model implies that the proximity of Igf2 to $\mathrm{H} 19$ facilitiates its imprinting, that is, that the control of allele specificity of both genes resides at the H19 locus.

\section{An evolutionary link between the imprinting and $\mathrm{X}$ chromosome inactivation?}

The parallels between imprinting and $X$ chromosome inactivation in early embryos raises the possibility that the two phenomena are related in evolution. $\mathrm{X}$ chromosome inactivation represents one solution to the ancient problem of dosage compensation in eukaryotes. Unlike dosage compensation in Caenorhabditis elegans, where both X chromosomes in XX hermaphrodites are downregulated to equalize expression of $\mathrm{X}$-linked genes in $\mathrm{XO}$ and XX animals, dosage compensation in mammals is characterized by the down regulation of only one of the two chromosomes. This form of dosage compensation has been documented in both eutherian and marsupial mammals. In marsupials, however, $\mathrm{X}$ chromosome inactivation differs in significant ways from $X$ chromosome inactivation in eutherians, because it is both incomplete and can be reactivated in tissue culture without de- 
methylating agents such as 5-azacytidine (for review, see D.W. Cooper et al. 1993). The most striking difference, however, is the preferential inactivation of the paternal $\mathrm{X}$ chromosome, similar to what is observed in the extraembryonic tissues of the mouse embryo (Cooper et al. 1971; Sharman 1971). The more distantly related monotremes such as the platypus have incomplete differentiation of the $\mathrm{X}$ and $\mathrm{Y}$ chromosomes, and for this reason the study of $X$ chromosome inactivation in this species has been difficult. However, cytological studies have suggested that one of the two $\mathrm{X}$ chromosomes is late replicating, a hallmark of X chromosome inactivation in other mammals, suggesting the possibility of inactivation in this species as well (Murtagh 1977).

Two hypotheses have been proposed to explain the evolution of parental imprinting. The simpler of the two proposes that imprinting arose in placental mammals as a mechanism to regulate tightly the rapid growth phase associated with the second half of gestation once organogenesis is complete (Solter 1988). Oversized fetuses not only endanger their own survival but the survival of their littermates and mother as well. Haig and his colleagues (Moore and Haig 1991) have provided a second model, whereby imprinting represents a tug-of-war between the desire of the male to sire many large fetuses with many females to ensure that his genes will be propagated in the population, versus the advantage to the female to conserve her resources with any single litter to ensure many future offspring. That is, the male's genome is using imprinting to deliver signals for growth while the female's genome is providing a compensatory brake.

Both models readily accommodate the imprinting of Igf2 and its binding protein, Igf2r, both of which are involved in growth regulation. In addition, the direction of their imprints, that is, the paternal expression of the positive growth regulator, Igf2, (DeChiara et al. 1991) and the maternal expression of the negative growth regulator, Igf2r (Barlow et al. 1991), are predictions of the Haig hypothesis. Likewise, the phenotype of uniparental disomies of chromosome 11, in which maternal inheritance of the proximal third of the chromosome leads to reduction in size of mice, while paternal inheritance leads to the reverse (Cattanach and Kirk 1985), would also lend support to either model.

Both models predict that oviparous animals, such as birds and amphibians, will not display imprinting, which is consistent with reports that parthenogenesis can be achieved in these species. However, they make different predictions about the time in vertebrate evolution when imprinting arose. The first model requires that the growth phase of embryonic development should occur in utero, and therefore one might expect that imprinting arose at the time that marsupials, whose progeny grow outside the uterus in late gestation, and eutherian mammals diverged. The Haig model, on the other hand, requires only that the mother contribute resources to the offspring, either before or after birth, and therefore all lactating mammals, including monotremes that lay egges (such as the platypus), should exhibit imprinting. However, one other condition would also have to hold: The species must be nonmonogamous for the two parental genomes to be engaged in their tug-of-war.

The evolution of the different reproductive strategies represented by eutherian mammals, marsupials, and monotremes is thought to have occurred in a very short period of time between 145 and 130 million years ago (Novacek 1992). It has not been established to date whether either marsupials or monotremes display imprinting, but it obvious that $\mathrm{X}$ chromosome inactivation in marsupials is essentially equivalent to autosomal imprinting, in that there is a parental bias /Chandra and Brown 1975). If marsupials have an Xist gene, its expression would therefore be imprinted as well, as it is in the early mouse embryo.

\section{Are $\mathrm{H} 19$ and Xist homologs?}

Thus, the stage is set to ask whether XIST and H19 arose as the result of convergent evolution, or whether they share a common ancestor. To establish common ancestry, we normally rely on two hallmarks of relatedness, the intron-exon structure of the genes and direct sequence comparison. Using both of these criteria, the case for the relatedness of $H 19$ and Igf2 is equivocal at best.

At first glance, it is apparent that the sizes of the genes and their transcripts are quite different (Fig. 2). The H19 gene is composed of five exons, separated by four very small intervening sequences and codes for a $2.5-\mathrm{kb}$ transcript in both humans and mice (Pachnis et al. 1988; Brannan et al. 1990). Xist/XIST, on the other hand, is a large gene, with a transcript $\sim 17 \mathrm{~kb}$ in length (Brockdorff et al. 1992; Brown et al. 1992). The number of exons of the Xist gene is not conserved in mammals, because the human gene has two extra exons at its $3^{\prime}$ end that are differentially spliced. What is similar between the overall structures of $H 19$ and Xist is the placement of large outside exons that are separated by very small exons. The differential splicing of the human transcript already suggests a mechanism whereby the absolute number and size of the exons could change, especially in a gene

Figure 2. The structures of the $H 19$ and $X I S T$ genes. The exons for the human $X I S T$, mouse $X i s t$, and $H 19$ genes are indicated by the solid boxes, with the spaces between representing the introns. (Adapted from Pachnid et al. 1988; Brannan et al. 1990; Brockdorff et al. 1992; Brown et al. 1992).

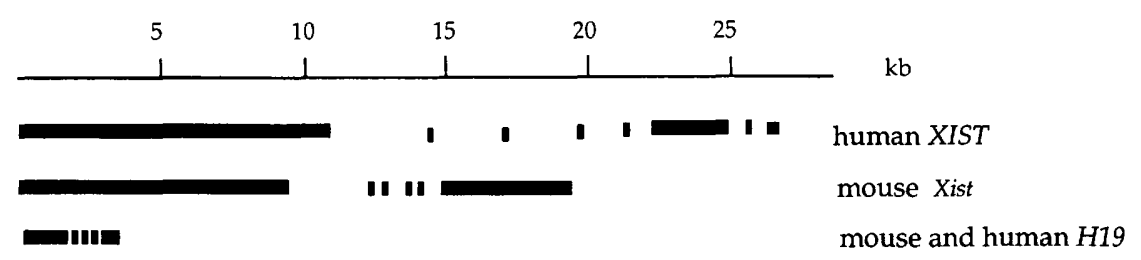


where the normal constraints imposed by maintaining the triplet genetic code are not working.

At the level of sequence similarity, the case for an evolutionary relationship between $H 19$ and Xist is harder to make. The problem lies in the fact that there is only modest primary sequence conservation, even within the mammalian Xist or $\mathrm{H} 19$ gene families. As Figure 3 illustrates, both genes exhibit regions of considerable sequence identity, interrupted by regions of relative nonidentity as well as by insertions/deletions in one sequence relative to the other. This confounds attempts to find similarities between the gene families. The overall degree of sequence identity between mouse and human $H 19$ is only $77 \%$ (Brannan et al. 1990). For XIST, the overall degree of conservation is even less, although, as is the case for $H 19$, regions such as exon 4 are relatively well conserved (Brockdorff et al. 1992; Brown et al. 1992; Hendrich et al. 1993). When the sequences of the small internal exons of H19 and XIST are examined for similarities, and when the most conserved regions of both genes were compared, no significant homologies $1>60 \%$ over 24 bases without the introduction of gaps) were evident.

One striking aspect of the sequence conservation within the $H 19$ gene family is the apparent preservation of secondary structure (Tilghman et al. 1992). This is evident in the presence of long energetically favorable stem-loop structures, which are conserved between ho- mologs by virtue of compensatory base substiututions in the stems. A particularly noteworthy example within H19 is shown in Figure 4. When the XIST/Xist RNAs were examined for similar structures, several were detected (Fig. 4). As was the case for H19, the longest of these coincided with the most conserved region of the RNA. However, when the primary sequences of these two regions were compared between the gene families, no similarities were apparent. Although the conservation of secondary structure shared by both RNAs is striking, it by no means argues in favor of a common ancestor for these genes, only that the secondary structure of both RNAs is important to their functions.

Three aspects of these structures suggest that they may be important in the overall activity of the two RNAs. First they occur in regions whose primary sequence is also being conserved; second, when base changes occur, they often occur at compensatory positions in the stem-loop; third, they each represent the most energetically favorable stem-loop predicted on the basis of the STEMLOOP program, primarily because of the long length of the stem, 35 and $36 \mathrm{bp}$. When comparable studies were performed on human and rodent AFP and albumin mRNAs, two RNAs whose sequences are diverging rapidly enough to provide some basis for comparison with $\mathrm{H} 19$ and Xist $(\sim 75 \%$ identity between either mouse and human AFP or between rat and human albumin), only two stem-loop structures were conserved

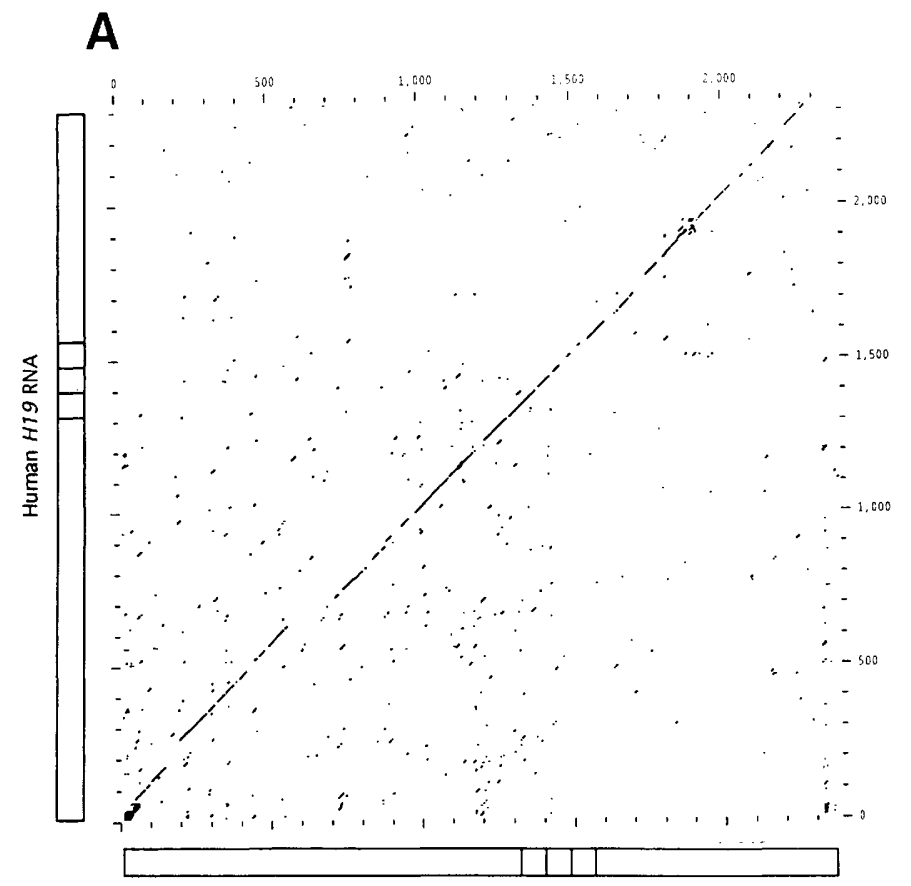

Mouse H19 RNA

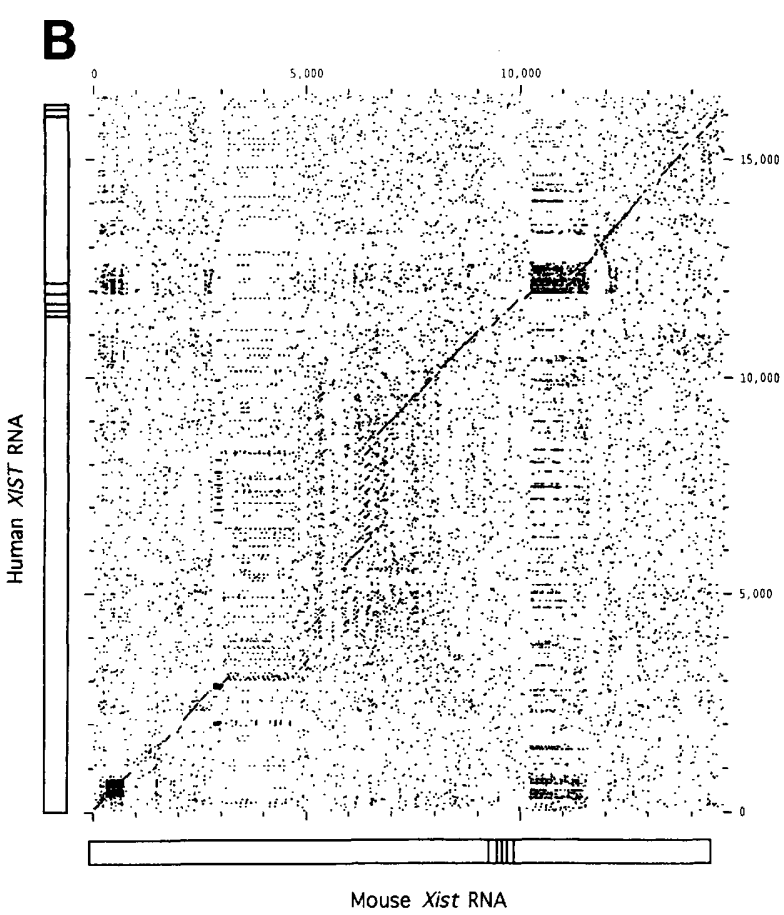

Figure 3. Sequence conservation within the human and mouse $H 19$ genes $(A)$ and between the human and mouse XIST genes $(B)$. The sequences of the mature mouse and human XIST RNAs and the mature mouse and human H19 RNAs were compared using the COMPARE program of the Genetics Computer Group (GCG) using a window of 21 bases and a stringency of $66 \%$, and plotted using the program DOTPLOT. The correspondence of the bases with the exons of each gene are indicated on the sides of the plots. (Sequences taken from Pachnis et al. 1988; Brannan et al. 1990; Brockdorff et al. 1992; Brown et al. 1992). 


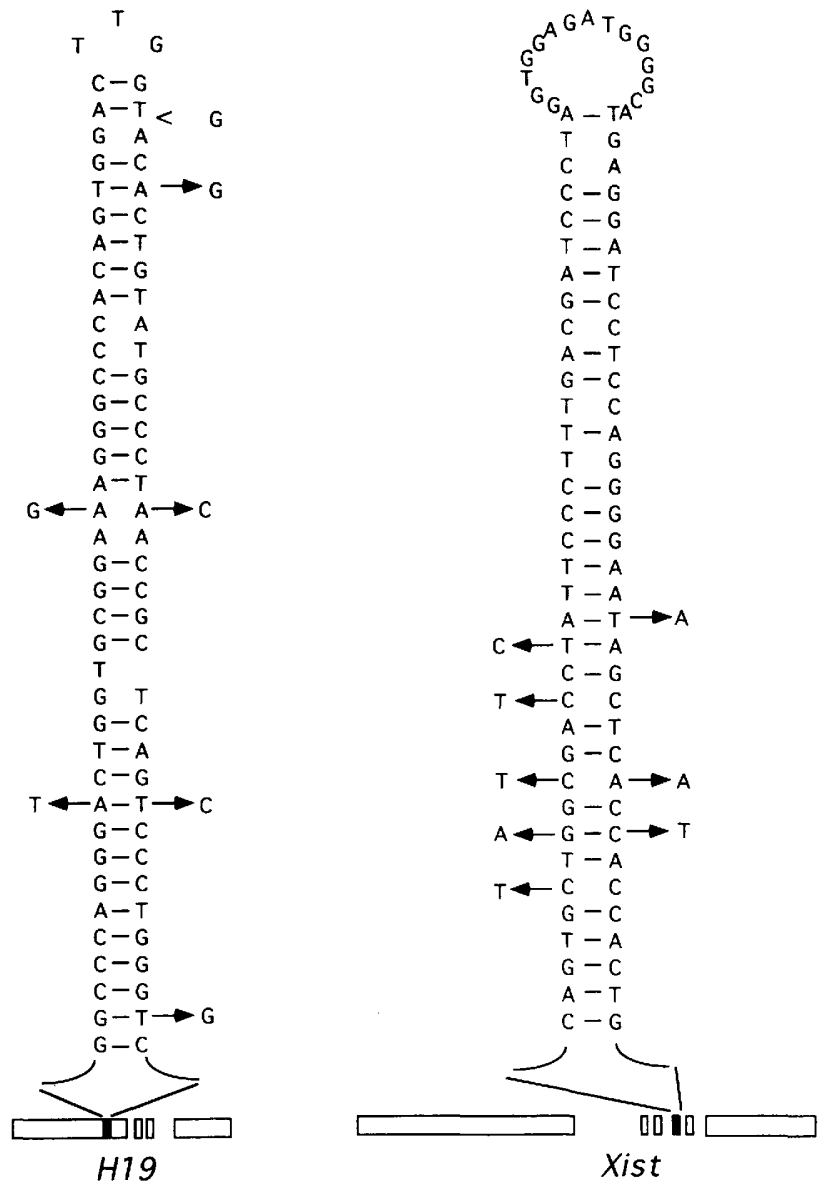

Figure 4. Conserved stem-loop structures in the H19 and Xist genes. The most conserved region of the mouse $H 19$ gene, within exon 1 , is drawn in an extended stem-loop. The bases differing between the mouse and human genes are indicated by the arrows. The most conserved region of the mouse Xist gene, within exon 4, is drawn similarly, with the base differences in the human gene indicated by the arrows.

between human and rat albumin mRNA, with stems ranging between 10 and 13 bases in length. No energetically favorable conserved stem-loop was detected in comparisons between human and mouse AFP.

Both human and mouse XIST/Xist contain a number of short tandem repeats throughout their lengths (Brockdorff et al. 1992; Brown et al. 1992). Although the repeat lengths vary in number between XIST and Xist, their positions and sequence motifs are conserved. There is no comparable extensive pattern of simple sequence repeats in H19; however, a short region at the $5^{\prime}$ end of both the human and mouse H19 RNAs contains the sequence TGGGGG repeated $8-10$ times. In neither gene is the significance of these repeats clear.

\section{Future prospects}

In the absence of primary sequence conservation between XIST/Xist and H19 to aid in establishing evolutionary relatedness, one must await the analysis of mu- tations in the two genes to ascertain whether they are performing similar functions in $\mathrm{X}$ chromosome inactivation and imprinting. Demonstrating a similar function would certainly strengthen the likelihood that the two RNAs shared a common ancestor, although by no means would this prove it. It will also be essential for any model that ascribes a function to these RNAs to establish when in mammalian speciation they arose and whether the times coincided with the evolution of $\mathrm{X}$ chromosome inactivation and imprinting, respectively. This particular piece of the puzzle may also help to determine which of the two forms of dosage compensation came first. Finally, one strong prediction of a model that proposes a function for RNAs in genomic imprinting is the presence of RNA-coding genes at other imprinted loci. Molecular analysis of three other imprinted loci in the mouse and human are under way in several laboratories. The most extensive of these, at the locus encoding the maternally expressed Igf2r gene in the mouse, has failed to reveal any additional imprinted genes to date (Barlow et al. 1991).

\section{References}

Barlow, D.P., R. Stoger, B.G. Herrmann, K. Saito, and N. Schweifer. 1991. The mouse insulin-like growth factor type-2 receptor is imprinted and closely linked to the Tme locus. Nature 349: 84-87.

Bartolomei, M. and S.M. Tilghman. 1992. Parental imprinting of mouse chromosome 7. Sem. Dev. Biol. 3: 107-117.

Bartolomei, M.S., S. Zemel, and S.M. Tilghman. 1991. Parental imprinting of the mouse $H 19$ gene. Nature 351: 153-155.

Bartolomei, M.S., A.L. Webber, M.E. Brunkow, and S.M. Tilghman. 1993. Epigenetic mechanisms underlying the imprinting of the mouse H19 gene. Genes \& Dev. 7: 1663-1673.

Brandeis, M., T. Kafri, M. Ariel, J.R. Chaillet, J. McCarrey, A. Razin, and H. Cedar. 1993. The Ontogeny of allele-specific methylation associated with imprinted genes in the mouse. EMBO I. 12: 3669-3677.

Brannan, C.I., E.C. Dees, R.S. Ingram, and S.M. Tilghman. 1990. The product of the $\mathrm{H} 19$ gene may function as an RNA. Mol. Cell. Biol. 10: 28-36.

Brockdorff, N., A. Ashworth, G.F. Kay, P. Cooper, S. Smith, V.M. McCabe, D.P. Norris, G.D. Penny, D. Patel, and S. Rastan. 1991. Conservation of position and exclusive expression of mouse Xist from the inactive $\mathrm{X}$ chromosome. Nature 351: 329-331.

Brockdorff, N., A. Ashworth, G.F. Kay, V.M. McCabe, D.P. Norris, P.J. Cooper, S. Swift, and S. Rastan. 1992. The product of the mouse Xist gene is a $15 \mathrm{~kb}$ inactive $X$-specific transcript containing no conserved ORF and located in the nucleus. Cell 71: 515-526.

Brown, C.J., A. Ballabio, J.L. Rupert, R.G. Lafreniere, M. Grompe, R. Tonlorenzi, and H.F. Willard. 1991. A gene from the region of the human $\mathrm{X}$ chromosome inactivation centre is expressed exclusively from the inactive $\mathrm{X}$ chromosome. Nature 349: 38-44.

Brown, C.J., B.D. Hendrich, J.L. Rupert, R.G. Lafreniere, Y. Xing, J. Lawrence, and H.F. Willard. 1992. The human XIST gene: Analysis of a $17 \mathrm{~kb}$ inactive $X$-specific RNA that contains conserved repeats and is highly localized within the nucleus. Cell 71: 527-542.

Cattanach, B.M. and M. Kirk. 1985. Differential activity of ma- 
ternally and paternally derived chromosome regions in mice. Nature 315: 496-498.

Cattanach, B.M. and D. Papworth. 1981. Controlling elements in the mouse. V. Linkage tests with X-linked genes. Genet. Res. 38: 57-70.

Cattanach, B.M., C.E. Pollard, and J.N. Peres. 1969. Controlling elements in the mouse $\mathrm{X}$ chromosome. I. Interaction with X-linked genes. Genet. Res. 14: 233-235.

Chaillet, J.R., T.F. Vogt, D.R. Beier, and P. Leder. 1991. Parentalspecific methylation of an imprinted transgene is established during gametogenesis and progressively changes during embryogenesis. Cell 66: 77-83.

Chandra, H.S. and S.W. Brown. 1975. Chromosome imprinting and the mammalian X chromosome. Nature 253: 165-168.

Cooper, D.W., J.L. VandeBerg, G.B. Sharman, and W.E. Poole. 1971. Phosphoglycerate kinase polymorphism in kangaroos provides further evidence for paternal $\mathrm{X}$ inactivation. Nature New Biol. 230: 155-157.

Cooper, D.W., P.G. Johnston, J.M. Watson, and J.A.M. Graves. 1993. X-inactivation in marsupials and monotremes. Sem. Dev. Biol. 4: 117-128.

Cooper, P., J.T. Keer, V.M. McCabe, R.M. Hamvas, S.D. Brown, S. Rastan, and N. Brockdorff. 1993. Physical mapping of 2000 $\mathrm{kb}$ of the mouse $\mathrm{X}$ chromosome in the vicinity of the Xist locus. Genomics 15: 570-575.

Davis, R.L., H. Weintraub, and A.B. Lassar. 1987. Expression of a single transfected cDNA converts fibroblasts to myoblasts. Cell 51: 987-1000.

DeChiara, T.M., A. Efstratiadis, and E.J. Robertson. 1990. A growth-deficiency phenotype in heterozygous mice carrying an insulin-like growth factor II gene disrupted by targeting. Nature 345: 78-80.

DeChiara, T.M., E.J. Robertson, and A. Efstratiadis. 1991. Parental imprinting of the mouse insulin-like growth factor II gene. Cell 64: 849-859.

Ferguson-Smith, A.C., H. Sasaki, B.M. Cattanach, and M.A. Surani. 1993. Parental-origin-specific epigenetic modifications of the mouse $H 19$ gene. Nature 362: 751-755.

Hadchouel, M., H. Farza, D. Simon, P. Tiollias, and C. Pourcel. 1987. Maternal inhibition of hepatitis B surface antigen gene expression in transgenic mice correlates with de novo methylation. Nature 329: 454-456.

Heard, E., M.C. Simmler, Z. Larin, C. Rougeulle, B. Courtier, H. Lehrach, and P. Avner. 1993. Physical mapping and YAC contig analysis of the region surrounding Xist on the mouse $\mathrm{X}$ chromosome. Genomics 15: 559-569.

Hendrich, B.D., C.J. Brown, and H.F. Willard. 1993. Evolutionary conservation of possible functional domains of the human and murine XIST genes. Hum. Mol. Gen. 2: 663-672.

Johnson, P.G. and B.M. Cattanach. 1981. Controlling elements in the mouse. IV. Evidence of non-random X-inactivation. Genet. Res. 37: 151-160.

Kafri, T., M. Ariel, M. Brandeis, R. Shemer, L. Urven, J. McCarrey, H. Cedar, and A. Razin. 1992. Developmental pattern of gene-specific DNA methylation in the mouse embryo and germ line. Genes \& Dev. 6: 705-714.

Kay, G.F., G.D. Penny, D. Patel, A. Ashworth, N. Brockdorff, and S. Rastan. 1993. Expression of Xist during mouse development suggests a role in the initiation of $\mathrm{X}$ chromosome inactivation. Cell 72: 171-182.

Lafreniere, L.G., C.J. Brown, S. Rider, J. Chelly, P. TaillonMiller, A.C. Chinault, A.P. Monaco, and H.F. Willard. 1993. $2.6 \mathrm{Mb}$ YAC contig of the human $\mathrm{X}$ inactivation center region in Xq13: Physical linkage of the RPS4X, PHKAl, XIST and DXS128E genes. Hum. Mol Genet. 2: 1105-1115.

Lee, J.E., J. Pintar, and A. Efstratiadis. 1990. Pattern of the in- sulin-like growth factor II gene expression during early mouse embryogenesis. Development 110: 151-159.

Lee, J.E., U. Tantravahi, A.L. Boyle, and A. Efstratiadis. 1993. Parental imprinting of an Igf-2 transgene. Mol. Reprod. Dev. 35: 382-390.

Leibovitch, M.P., V.C. Nguyen, M.S. Gross, B. Solhonne, S.A. Leibovitch, and A. Bernheim. 1991. The human ASM (adult skeletal muscle/ gene: Expression and chromosomal assignment to $11 \mathrm{pl}$. Biochem. Biophys. Res. Comm. 180: 12411250.

Leppig, K.A., C.J. Brown, S.L. Bressler, K. Gustashaw, R.A. Pagon, H.F. Willard, and C.M. Disteche. 1993. Mapping of the distal boundary of the $\mathrm{X}$-inactivation center in a rearranged X chromosome from a female expressing XIST. Hum. Mol. Genet. 2: 883-887.

Li, E., T.H. Bestor, and R. Jaenisch. 1992. Targeted mutation of the DNA methyltransferase gene results in embryonic lethality. Cell 69: 915-926.

Li, E., C. Beard, and R. Jaenisch. 1993. The role of DNA methylation in genomic imprinting. Nature 366: 362-365

Monk, M., M. Boubelik, and S. Lehnert. 1987. Temporal and regional changes in DNA methylation in the embryonic, extraembryonic and germ cell lineages during mouse embryo development. Development 99: 371-382.

Moore, T. and D. Haig. 1991. Genomic imprinting in mammalian development: A parental tug-of-war. Trends Genet. 7: 45-89.

Murtagh, C.E. 1977. A unique cytogenetic system in monotremes. Chromosoma 65: 37-57.

Norris, D.P., D. Patel, G.F. Kay, G.D. Penny, N. Brockdorff, S.A. Sheardown, and S. Rastan. 1994. Evidence that random and imprinted Xist expression is controlled by preemptive methylation. Cell 77: 41-51.

Novacek, M.J. 1992. Mammalian phylogeny: Shaking the tree. Nature 356: 121-125.

Pachnis, V., A. Belayew, and S.M. Tilghman. 1984. Locus unlinked to $\alpha$-fetoprotein under the control of the murine raf and Rif genes. Proc. Natl. Acad. Sci. 81: 5523-5527.

Pachnis, V., C.I. Brannan, and S.M. Tilghman. 1988. The structure and expression of a novel gene activated in early mouse embryogenesis. EMBO J. 7: 673-681.

Pizzuti, A., D. Muzny, C. Lawrence, H.F. Willard, P. Avner, and A. Ballabio. 1991. Characterization of a murine gene expressed from the inactive X chromosome. Nature 351: 325328.

Poirier, F., C.-T.J. Chan, P.M. Timmons, E.J. Robertson, M.J. Evans, and P.W.J. Rigby. 1991 . The murine $\mathrm{H} 19$ gene is activated during embryonic stem cell differentiation in vitro and at the time of implantation in the developing embryo. Development 113: 1105-1114.

Reik, W., A. Collick, M.L. Norris, S.C. Barton, and M.A. Surani. 1987. Genomic imprinting determines methylation of parental alleles in transgenic mice. Nature 328: 248-251.

Sapienza, C., A.C. Peterson, J. Rossant, and R. Balling. 1987. Degree of methylation of transgenes is dependent on gamete of origin. Nature 328: 251-254.

Sasaki, H., T. Hamada, T. Ueda, R. Seki, T. Higashinakagawa, and Y. Sakaki. 1991. Inherited type of allelic methylation variations in a mouse chromosome region where an integrated transgene shows methylation imprinting. Development 111: 573-581.

Sasaki, H., P.A. Jones, J.R. Chaillet, A.C. Ferguson-Smith, S. Barton, W. Reik, and M.A. Surani. 1992. Parental imprinting: Potentially active chromatin of the repressed maternal allele of the mouse insulin-like growth factor (Igt2) gene. Genes \& Dev. 6: 1843-1856. 
Searle, A.G. and C.V. Beechey. 1990. Genome imprinting phenomena on mouse chromosome 7. Genet. Res. 56: 237-244.

Sharman, G.B. 1971. Late DNA replication in the paternally derived $\mathrm{X}$ chromosome of female kangaroos. Nature 230: 231-232.

Solter, D. 1988. Differential imprinting and expression of maternal and paternal genomes. Annu. Rev. Genet. 22: 127146.

Stoger, R., P. Kubicka, C.-G. Liu, T. Kafri, A. Razin, H. Cedar, and D.P. Barlow. 1993. Maternal-specific methylation of the imprinted mouse Igf2r locus identifies the expressed locus as carrying the imprinting signal. Cell 73: 61-71.

Swain, J.L., T.A. Stewart, and P. Leder. 1987. Parental legacy determines methylation and expression of an autosomal transgene: A molecular mechanism for parental imprinting. Cell 50: 719-727.

Takagi, N. and M. Sasaki. 1975. Preferential inactivation of the paternally derived $\mathrm{X}$ chromosome in the extraembryonic membranes of the mouse. Nature 256: 640-642.

Tilghman, S.M., M.E. Brunkow, C.I. Brannan, C. Dees, M.S. Bartolomei, and K. Phillips. 1992. The mouse $H 19$ gene: Its structure and function in mouse development. In Nuclear processes and oncogenes (ed. P.A. Sharp), pp. 188-200. Academic Press, New York.

West, J.D., W.I. Frels, and V.M. Chapman. 1977. Preferential expression of the maternally derived $\mathrm{X}$ chromosome in the mouse yolk sac. Cell 12: 873-882.

Zemel, S., M.S. Bartolomei, and S.M. Tilghman. 1992. Physical linkage of two mammalian imprinted genes. Nature Genet. 2: 61-65. 


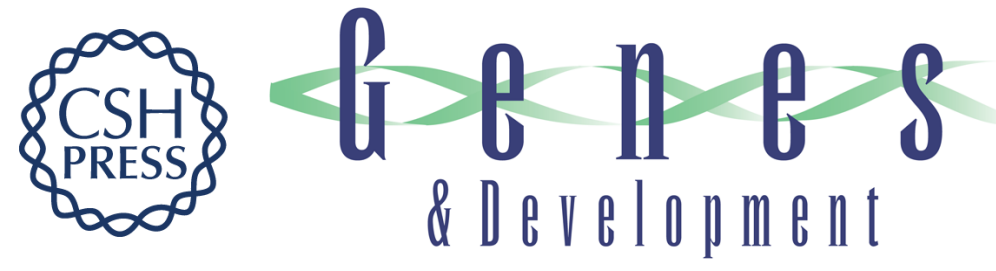

\section{Allele-specific gene expression in mammals: the curious case of the imprinted RNAs.}

K Pfeifer and S M Tilghman

Genes Dev. 1994, 8:

Access the most recent version at doi:10.1101/gad.8.16.1867

References This article cites 56 articles, 9 of which can be accessed free at:

http://genesdev.cshlp.org/content/8/16/1867.full.html\#ref-list-1

License

Email Alerting

Service

Receive free email alerts when new articles cite this article - sign up in the box at the top right corner of the article or click here.

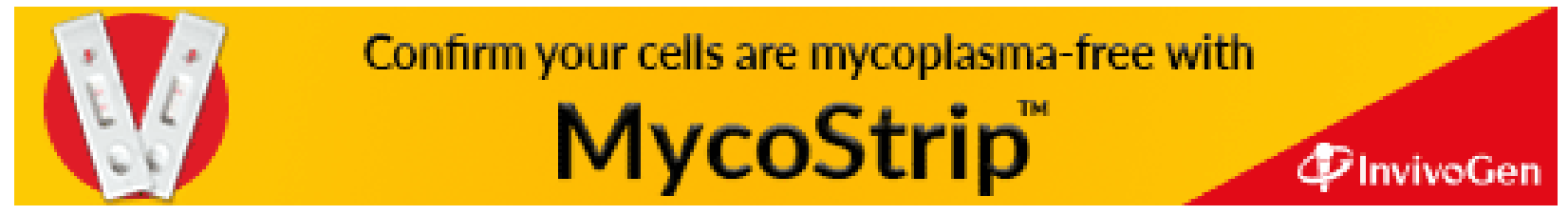

